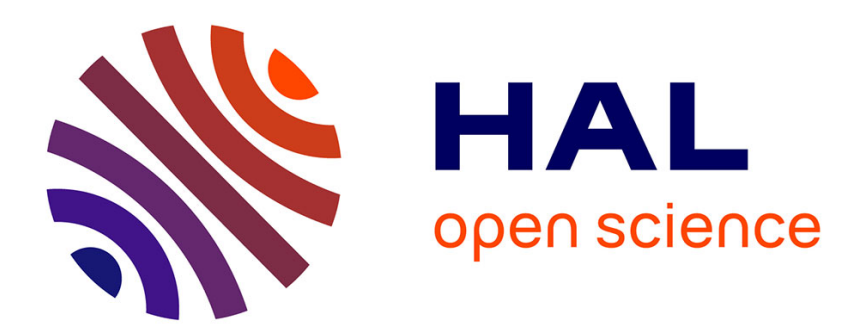

\title{
A quasi-brittle continuum damage finite element model of the human proximal femur based on element deletion
} Ridha Hambli

\section{To cite this version:}

Ridha Hambli. A quasi-brittle continuum damage finite element model of the human proximal femur based on element deletion. Med Biol Eng Comput, 2013, 51 (1-2), pp.219-31. hal-00837713

\section{HAL Id: hal-00837713 \\ https://hal.science/hal-00837713}

Submitted on 24 Jun 2013

HAL is a multi-disciplinary open access archive for the deposit and dissemination of scientific research documents, whether they are published or not. The documents may come from teaching and research institutions in France or abroad, or from public or private research centers.
L'archive ouverte pluridisciplinaire HAL, est destinée au dépôt et à la diffusion de documents scientifiques de niveau recherche, publiés ou non, émanant des établissements d'enseignement et de recherche français ou étrangers, des laboratoires publics ou privés. 


\title{
A quasi-brittle continuum damage finite element model of the human proximal femur based on element deletion
}

\section{Ridha HAMBLI}

Prisme Institute - MMH

8, Rue Leonard de Vinci, 45072, Orleans cedex 2, France

phone : +33 (0)2-38-49-40-55

mail : ridha.hambli@univ-orleans.fr

\begin{abstract}
In this paper, a simple and practical finite element (FE) model coupled to a quasi-brittle damage law to describe the initiation and progressive propagation of multiple cracks based on element deletion is developed in order to predict the complete force-displacement curve and the fracture pattern of a human proximal femur under quasi-static load. The motivation of this work was to propose a FE model for possible clinical use with a good compromise between complexity and capability of the simulation. The model considers a limited number of parameters that can predict proximal femur fracture in more adequate physical terms than criteria-based fracture models. Based on experimental results, different damage laws for cortical and trabecular bone are proposed to describe inelastic damage accumulation under excessive load. When the damage parameter reaches its critical value inside an element of the mesh, its stiffness matrix is set to zero, leading to the redistribution of the stress state in the vicinity of the damaged zone (crack initiation). Once a crack is initiated, the propagation direction is simulated by the propagation of the broken elements of the mesh. To illustrate the potential of the proposed approach, the left femur of a male (age 61) previously investigated by Keyak and Falkinstein [37] (Model B: male, age 61) was simulated till complete fracture under one-legged stance quasistatic load. The proposed finite element model leads to more physical results concerning the shape of the force-displacement curve (yielding and fracturing) and the profile of the fractured edge.
\end{abstract}

Keywords: Finite element, Proximal femur fracture, Crack propagation, Fracture pattern, Forcedisplacement curve, Quasi-static 


\section{Introduction}

In order to predict human proximal femur fracture, linear and non-linear isotropic and anisotropic finite element (FE) models (Table 1) have been developed by several authors. For simplicity and due to the limited knowledge of the anisotropic behavior of bone, most FE models for femur fracture simulation considered the bone as inhomogeneous and isotropic material. Empirical density-elasticity relationships are generally applied to assign a single isotropic elastic modulus to every FE of the mesh driven by CT scans. Several recent approaches have been developed to assign the anisotropic orientation of bone as a function of its cortical and trabecular structural morphology and mechanical behavior. These approaches include orientation methods using anatomical directions corresponding to the bone shape $[7,26,38,90]$, variation in the CT Hounsfield unit values based on micromechanical considerations [30, 66, 73, 76], bone remodeling simulation prior to fracture prediction to obtain the bone orthotropic orientation and elastic assignment $[11,17,20,40,51]$, and a procedure to orientate orthotropic properties in a proximal femur FE model using the directions of the principal stresses produced by a physiological load scheme [64]. Empirical relations between the orthotropic constants and bone density have been suggested by several authors [29-34]. Nevertheless, the determination of material trajectories related to the trabecular orientations from clinical quantitative computed tomography (QCT) scans remains an open question $[64,71,74,86]$.

Several FE analyses with inhomogeneous isotropic material properties have been shown to predict the strains and displacements on the surface of the proximal femur with high accuracy when compared with in vitro experiments $[35,48,67,76]$. The same FE models with inhomogeneous orthotropic material properties produce results similar to those obtained with isotropic material properties $[3,58,83]$.

Previous FE models have applied different uncoupled fracture criteria including von Mises equivalent stress, equivalent stress, maximum principal strain criterion Hill's criterion and Drucker-Prager criterion in order to predict the onset of human proximal femur fracture under 
excessive load. Such criteria are limited in general to the prediction of the initiation of local bone failure only. They do not take into consideration the complete quasi-brittle fracturing process of proximal femur and the loss of bone material stiffness generated by progressive damage accumulation prior to fracture. Recently, several authors investigated the fracture of cortical bone based on fracture mechanics concepts [2, 47, 72, 78, 81, 82, 89] but failed to predict the complete fracture pattern of bone since these methods are restricted to the problem of a single dominant idealized planar crack. Recently, element softening methods have been developed by Wang et al. [84] to study 2D iliac crest bone specimens failure. A principal tensile strain of 0.005 was used as the tissue failure criterion and when the principal strain of one element reached the failure criterion, the element was marked as "failed" and the bone material elastic modulus in the element was set to a postfailure modulus. Bone microcracks were identified using the list of damaged elements and the rate of change in FE element stiffness due to microcracks accumulation were calculated using linear regression relationship.

In spite of the large number of FE studies dealing with bone fracture under monotonic load (Table 1), there is still a lack of practical and simple FE models that simulate the complete and realistic behavior of bone from the elastic stage till complete fracture. Several studies showed that bone exhibits a quasi-brittle material behavior $[5,14,16,32-34,62]$ or brittle behavior [31, 43, 68, 88] depending mainly on the deformation rate applied and the bone properties. Therefore, more suitable physical models are still lacking to describe the brittle to quasi-brittle fracture behavior of human femur. Such models can be developed by incorporating the continuum damage mechanics (CDM) concept in order to predict the progressive initiation and propagation of cracks, leading to complete fracture of the bone organ.

In the present work, an isotropic FE model coupled to a quasi-brittle damage law was developed in order to simulate fracture of human proximal femurs under quasi-static load and predict the complete force-displacement curve and the final fracture pattern of the proximal 
femur under one-legged stance load. The element deletion technique was applied in order to simulate the progressive fracturing process of bone.

The current isotropic strategy is motivated by: (i) Some published comparative studies claiming that the assigned orthotropic material model has a limited effect on the FE result at bone organ level compared to the isotropic one $[3,58,83]$, and (ii) the complexity regarding the assignment of the local anisotropic directions for every FE of the mesh and their corresponding anisotropic material properties $[64,77]$.

Table 1 summarizes the main differences between the CDM model presented here and previously published ones.

\begin{tabular}{|c|c|c|c|c|c|c|}
\hline $\begin{array}{l}\text { Models } \\
\text { reported in }\end{array}$ & $\begin{array}{c}{[4,6,10,19,24} \\
31,35-37,39,44- \\
46,55,68,77]\end{array}$ & {$[7,26,38,90]$} & {$[66,73,76,77]$} & $\begin{array}{c}{[11,17,20} \\
40,51]\end{array}$ & {$[43,64]$. } & $\begin{array}{l}\text { Present model } \\
\text { (CDM approach) }\end{array}$ \\
\hline $\begin{array}{c}\text { Behaviour } \\
\text { law }\end{array}$ & $\begin{array}{l}\text { Isotropic with } \\
\text { homogenous/ } \\
\text { inhomogenous } \\
\text { properties }\end{array}$ & \multicolumn{4}{|c|}{ Anisotropic with homogenous/inhomogenous properties } & $\begin{array}{c}\text { Isotropic behavior law } \\
\text { coupled to quasi- } \\
\text { brittle damage law }\end{array}$ \\
\hline $\begin{array}{c}\text { Material } \\
\text { properties } \\
\text { assignment }\end{array}$ & \multicolumn{6}{|c|}{ Empirical relation between density and material properties } \\
\hline $\begin{array}{l}\text { Orthotropic } \\
\text { direction } \\
\text { assignment }\end{array}$ & Not applicable & $\begin{array}{l}\text { Methods using } \\
\text { anatomical } \\
\text { directions } \\
\text { corresponding to } \\
\text { the bone shape }\end{array}$ & $\begin{array}{l}\text { Variation of the } \\
\text { CT Hounsfield } \\
\text { unit values based } \\
\text { on } \\
\text { micromechanical } \\
\text { considerations }\end{array}$ & $\begin{array}{l}\text { Bone } \\
\text { remodeling } \\
\text { simulation } \\
\text { prior to } \\
\text { fracture } \\
\text { prediction }\end{array}$ & $\begin{array}{l}\text { Based on the } \\
\text { directions of the } \\
\text { principal } \\
\text { stresses }\end{array}$ & Not applicable \\
\hline $\begin{array}{l}\text { Fracture } \\
\text { modeling }\end{array}$ & \multicolumn{5}{|c|}{ Uncoupled fracture criteria } & Coupled damage law \\
\hline $\begin{array}{l}\text { Prediction } \\
\text { (Force) }\end{array}$ & \multicolumn{4}{|c|}{ Maximum fracture force } & Not predicted & $\begin{array}{c}\text { Complete force- } \\
\text { displacement curve }\end{array}$ \\
\hline $\begin{array}{c}\text { Prediction } \\
\text { (Fracture } \\
\text { pattern) }\end{array}$ & \multicolumn{5}{|c|}{ Not predicted } & $\begin{array}{l}\text { Complete fracture } \\
\text { pattern }\end{array}$ \\
\hline
\end{tabular}

Table 1. Comparison between the main previously published femur fracture FE models based on fracture criteria and the present FE model based on CDM.

To illustrate the potential of the proposed approach, the left femur of a male (age 61) previously investigated by Keyak and Falkinstein [37] (Model B) was simulated till complete fracture under one-legged stance load. The proposed FE model leads to more precise and realistic results concerning the shape of the force-displacement curve and the fracture pattern. 


\section{Methods}

The model is based on an isotropic behaviour law coupled to a quasi-brittle damage law to describe the progressive initiation and propagation of cracks within human proximal femur under quasi-static load. The proposed damage laws were fitted based on experimental results performed on trabecular and cortical bone which distinguish between tension and compression. The model was implemented into the Abaqus/Standard code using the subroutine UMAT [1].

\subsection{Quasi-brittle behavior law of bone under quasi-static load}

In general, at a low load rate (quasi-static regime), the proximal femur behaves as a quasi-brittle material with a non-linear behavior till complete fracture [6, 19, 36-37]. In this case, quasi-brittle behavior laws are well suited to represent the non-linear behavior before complete fracture observed during quasi-static proximal fracture experiments. Nagaraja et al. [53] used micro-CT and sequential fluorescent staining to assess local trabecular bone damage under varying levels of uniaxial compression. The authors performed incremental compression loads under controlled strain levels on fifteen fluorescent stained cylindrical specimens of bovine bone. After each strain step, specimens were micro-CT imaged in order to track the progression of local diffuse damage in different cross sections. Lastly, the measured diffuse damage area for each section normalized by its bone area was averaged for all sections. A similar approach was applied by Parsamian [57] to assess the damage law of human cortical bone.

The damage behavior of cortical and trabecular bone corresponds to the generation of microcracks [80], which leads to a reduction in stiffness, energy dissipation, and permanent strains, and may result in bone failure [34]. The damage threshold stress which coincides with the elastic limit or yield stress quantifies the onset of damage behavior. After having reached the ultimate stress at fracture, the stress decreases gradually for increasing strain which corresponds 
to a softening stage till complete fracture. This phase corresponds to the generation of microcracks which lead to a reduction in stiffness [87].

The development and growth of cracks can induce anisotropy in the mechanical behavior of the material [87]. In the context of CDM, this leads to the introduction of high order tensorial damage variables, requiring the identification of $3 \mathrm{D}$ damage laws and the corresponding material properties $[15,42]$. In the current work, due to lack of data related to anisotropic damage laws and bone behavior, a simple practical FE model based on isotropic damage variables is proposed. The focus here was to provide a proximal femur engineering modeling approach rather than to develop a sophisticated (complicated) fracture model which would be hard for clinicians to apply. Such an isotropic simulation approach represents a good compromise between complexity and capability of the simulation, given the limited number of model parameters and the availability of experimental data compared to anisotropic bone behavior [3, 58, 83].

Although bone tissue has been shown to behave as a viscoelastic inelastic damageable material for a large range of strain rates [21, 23], rate-dependent effects have a moderate impact on physiological strain rates as they occur during normal daily activities $(\sim 1 \mathrm{~Hz})$ [21]. Hence, in the quasi-static load regime (low strain rate), bone viscosity can be neglected.

Therefore, in the quasi-static regime and neglecting viscosity effects, the stress-strain relation of elasticity based damage mechanics is expressed by [15, 42]:

$$
\sigma_{i j}=(1-D) C_{i j k l} \varepsilon_{k l}
$$

where $D$ denotes the damage variable, $\sigma_{i j}$ the stress components, $\varepsilon_{k l}$ the strains and $C_{i j k l}$ are the elasticity tensor components.

Relation (1) shows that the damage variable acts as a stiffness reduction factor. For increasing damage, the effective stiffness moduli $(1-D) C_{i j k l}$ decrease. 
The growth of the quasi-brittle damage variable is controlled by the damage threshold parameter $\kappa$, defined by:

$$
\kappa=\max \left(\varepsilon_{e q}\right)
$$

where $\max ()$ denotes the maximum of the equivalent strain measure $\varepsilon_{e q}$ reached during the load history.

The equivalent strain $\varepsilon_{e q}$ is expressed by:

$$
\varepsilon_{e q}=\sqrt{\frac{2}{3} \varepsilon_{i j} \varepsilon_{i j}}
$$

$\varepsilon_{i j}$ denote the stress components.

Damage growth depends on a damage loading function in terms of the strain components expressed by Mazars et al. [50]:

$$
\begin{aligned}
& f\left(\varepsilon_{e q}, \varepsilon_{0}\right)=\varepsilon_{e q}-\max \left(\kappa, \varepsilon_{0}\right) \\
& \max \left(\kappa, \varepsilon_{0}\right) \text { denotes the greatest value of } \kappa \text { and } \varepsilon_{0} .
\end{aligned}
$$

where $\varepsilon_{0}$ is the initial value of $\kappa$ when damage starts. If the loading function $f$ is negative, damage does not develop. During monotonic loading, the parameter $\kappa$ grows (it coincides with $\varepsilon_{e q}$ ) and during unloading and reloading it remains constant:

$f<0$ : No damage growth and the material behavior is elastic.

$f \geq 0$ : Damage growth and reduction of stiffness. 
When the condition ( $f \geq 0$ ) is satisfied, the growth of damage is governed by an evolution law which is expressed in the general form $[15,42]$ :

$$
\dot{D}=g\left(D, \varepsilon_{e q}, \dot{\varepsilon}_{e q}, \sigma_{i j}\right)
$$

\subsection{Damage laws of trabecular and cortical bone}

Considering the experimental results of Wolfram et al. [87] performed on 251 cylindrical trabecular bone samples obtained from human vertebrae (T1-L3) and the results performed on human cortical bone by Parsamian [57] (Fig. 1), an experimentally fitted damage law can be expressed in the general form:

$$
\begin{cases}D=0 & ; \varepsilon_{e q} \leq \varepsilon_{0} \\ D=D_{c} \varepsilon_{e q}^{n} & ; \varepsilon_{0}<\varepsilon_{e q}<\varepsilon_{f} \\ D=D_{c} & ; \varepsilon_{e q} \geq \varepsilon_{f}\end{cases}
$$

$D_{c}, n$ and $\varepsilon_{f}$ are respectively the critical damage at fracture, the damage exponent and the strain at fracture which can be assessed based on experimental results reported in [57, 87] (Fig. 1).

The constants in Eq. (6) were determined by a trial and error optimization procedure to improve the agreement between the fitted and experimental damage laws of Fig.1-a and 1-b. 


\begin{tabular}{|l|c|c|c|c|c|}
\hline Strain level (\%) & $\mathcal{E}_{1}$ & $\mathcal{E}_{2}$ & $\mathcal{E}_{3}$ & $\mathcal{E}_{4}$ & $\mathcal{E}_{5}$ \\
\hline In tension & 0.4 & 0.6 & 1 & 1.6 & 2.4 \\
\hline In compression & 0.4 & 0.7 & 1.4 & 2.5 & 4 \\
\hline
\end{tabular}
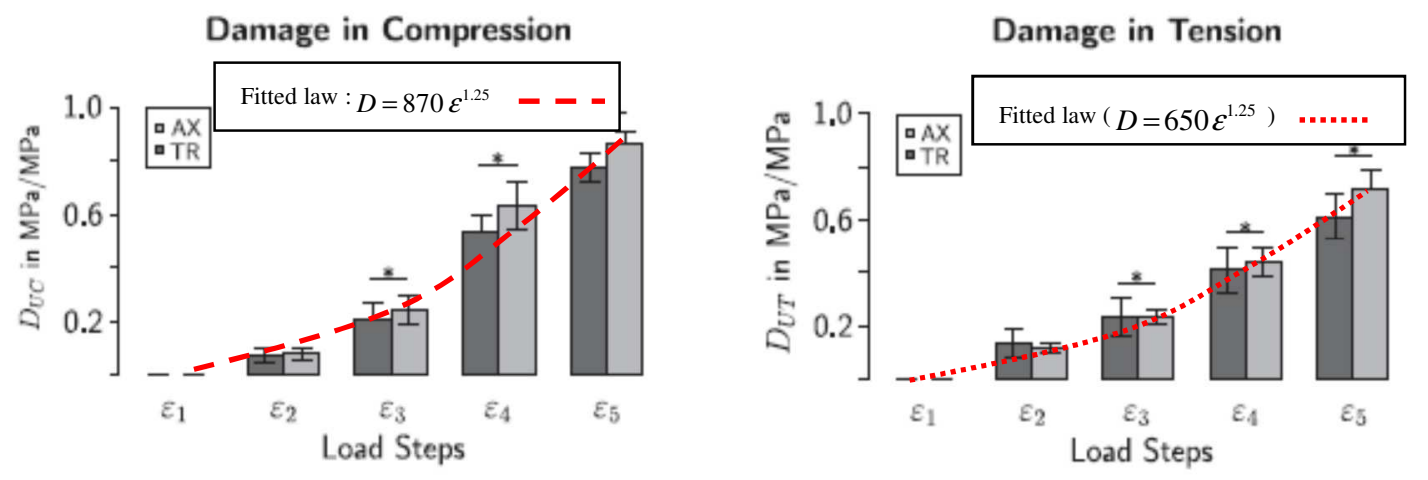

(a) Experimental averaged damage in tension and compression performed on 251 human vertebrae trabecular specimens [87] and computed fitted damage laws in compression and tension based on the experimental results.

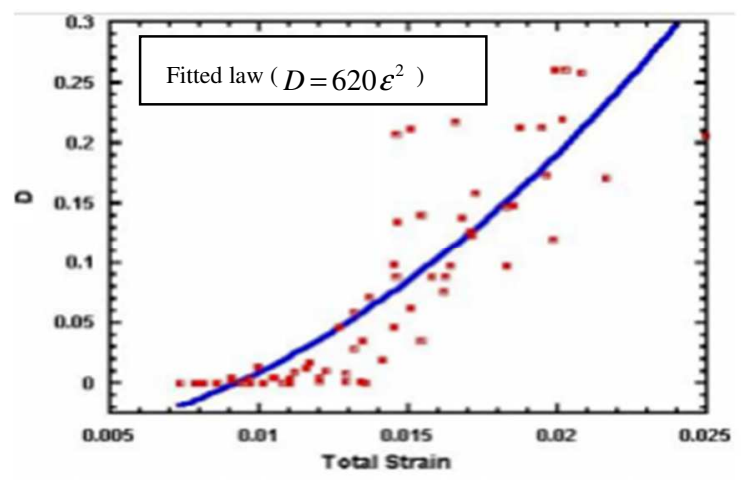

(b) Experimental averaged damage law for human cortical bone performed on fourteen cortical core specimens [57] and the corresponding fitted damage law.

Figure 1. Damage laws for human trabecular and cortical bone.

In addition, numerous studies show that damage threshold strains and stresses of trabecular and cortical bone tissue are different in tension and compression [13, 33-34, 61-62, 87]. Therefore, to account for the asymmetrical bone yields, the strain at fracture is given by:

$$
\begin{cases}\varepsilon_{f}=\varepsilon_{f}^{T} \text { and } D_{c}=D_{c}^{T} & \text { in Tension } \\ \varepsilon_{f}=\varepsilon_{f}^{C} & \text { and } D_{c}=D_{c}^{C}\end{cases}
$$

$\varepsilon_{f}^{T}$ and $\varepsilon_{f}^{C}$ are the tensile and compressive strains at fracture respectively.

$D_{c}^{T}$ and $D_{c}^{C}$ are critical damage values at fracture in tension and compression. 


\subsection{Crack propagation simulation}

A practical and sufficiently accurate way to represent fracture is the so-called 'kill element' technique [27-28]. In CDM, there is no difference between crack initiation and propagation. Both of them result from the failure of an element of the mesh. Thus, crack initiation and propagation are studied in a unified approach [15, 42].

A similar approach was applied by MacNeil and Boyd [49] to develop a non-linear FE model to predict human distal radius strength. A yield criterion was retained based on maximum compressive and tensile yield strains incorporated into the constitutive model. When the tissue maximum principal tensile or compressive strain exceeded the yield values, the elastic properties of the tissue were reduced by $95 \%$.

The technique developed here distinguishes between tension, shearing and compression loading modes as follows:

\section{In tension:}

When the damage parameter reaches its critical value $D_{c}^{T}$ inside an element, its stiffness matrix is set to zero, leading to the redistribution of the stress state in the vicinity of the fractured zone (crack initiation). Once a crack is initiated, the propagation direction is simulated by the propagation of the broken elements of the mesh. At continuum level, the local critical damage value in tension is generally equal to $1\left(D_{c}^{T} \approx 1.0\right)$ [56]. To avoid numerical convergence problems, the critical damage value at fracture was set to $D_{c}^{T}=0.95$.

\section{In compression and shearing:}

When the kill element method is used in compressive or shearing regions, it is necessary to model the self-contact in compression/shearing of the gap created by the element deletion. The alternative is to keep the elements, but to reduce their stiffness to a low, but not null value. In compression and shearing, the critical damage value at fracture was set to $D_{c}^{C}=0.5$ [28]. 


\subsubsection{Regularization of the crack propagation dependency on mesh size}

In the constitutive law of conventional $\mathrm{CDM}$ there is no intrinsic material characteristic length, which means that crack propagation results are dependent on the mesh size $[52,63,79]$. When the mesh is refined during damage FE analysis, crack growth prediction becomes more accurate in that the displacement gradients which describe the discontinuities become stronger. Consequently, the predicted critical damage at fracture occurs faster, leading to faster crack propagation [1]. Therefore, when conducting a FE simulation of crack propagation, the physical crack length ( $\left.L_{f r x}\right)$ must be considered in relation with the local FE mesh characteristic length ( $\left.L_{F E}\right)$. It has been reported that such an approach minimizes significantly the crack propagation dependency on the mesh size $[52,63,79]$.

An alternative and simple method to ensure the objectivity of the numerical model in relation with the physical cracking process and the mesh dependence problem consists in weighting (linear form) the strain at fracture as a function of a characteristic FE length $\left(L_{F E}\right)$ and the crack length $\left(L_{f r x}\right)$ in the form [1]:

$$
\begin{aligned}
& \mathcal{\varepsilon}_{f}^{T}=\varepsilon_{f-\text { true }}^{T}\left(\frac{L_{f r x}}{L_{F E}}\right) \\
& \varepsilon_{f}^{C}=\varepsilon_{f-\text { true }}^{C}\left(\frac{L_{f r x}}{L_{F E}}\right) \\
& L_{F E}=\left(A_{\text {elem }}\right)^{\frac{1}{2}} \text { for 2D problems } \\
& L_{F E}=\left(V_{\text {elem }}\right)^{\frac{1}{3}} \text { for 3D problems }
\end{aligned}
$$

where $\varepsilon_{f-\text { true }}^{T}$ and $\varepsilon_{f-\text { true }}^{C}$ denote respectively, the true bone material measured strain at fracture in tension and compression which can be assessed based on experimental results $[57,87]$.

$A_{\text {elem }}$ and $V_{\text {elem }}$ denote respectively, the area of the FE (in 2D problems) and the volume of the FE (in 3D problems). 
Note that the FE characteristic length $L_{F E}$ is referred to the parameter (CELENT) by Abaqus code [1] and that it is computed at every increment by Abaqus.

Average crack lengths found in bones are typically 100 microns long [72]. The characteristic length $L_{f r x}$ was therefore set to $\left(L_{f r x}=0.1 \mathrm{~mm}\right)$.

In addition, the characteristic length calculation is based only on the element geometry. As a result, some level of mesh sensitivity remains related to the cracking direction. Therefore, elements with an aspect ratio of one were selected in the current work. The proposed meshdependency regularization method is recommended by the Abaqus code [1] for crack propagation problems to ensure non-dependency of the fracture results on the finite element mesh.

\subsection{Mesh sensitivity to critical damage at fracture}

Because of uncertainty concerning the critical damage at fracture parameters $\left(D_{c}^{T}\right.$ and $D_{c}^{C}$ ), a sensitivity analysis (SA) was performed to investigate the impact of the factors' sensitivities on the femur fracture force. To perform SA, either a one-factor or a multi-factor SA approach can be used. One-factor sensitivity analysis is useful in investigating the impact of one parameter varying in the model, while multi-factor SA examines the impact of two or more different parameters changing simultaneously on the model responses. Multi-factor SA generally demands a huge amount of calculation time. In addition, it should be noted that the presentation and interpretation of multi-factor SA becomes increasingly complex as the number of parameters involved increases. In the current work, a limited preliminary one-factor SA was performed in which only one model parameter $\left(D_{c}^{T}\right.$ or $D_{c}^{C}$ ) value was varied by a given percent (Table 3 ) while the other parameter was kept at its reference values. For each parameter change, a fracture simulation was performed and the proximal femur fracture force was computed. The analysis consisted of 12 runs for every critical damage parameter change (Table 3 ). 


\begin{tabular}{|l|c|c|c|c|c|c|}
\hline & Value 1 & Value 2 & Value 3 & Value 4 & Value 5 & Value 6 \\
\hline $\begin{array}{l}\text { Critical damage at fracture in } \\
\text { tension: } D_{c}^{T}\end{array}$ & $\begin{array}{c}0.95 \\
\text { (Reference) }\end{array}$ & 0.76 & 0.8 & 0.855 & 0.9 & 1 \\
\hline $\begin{array}{l}\text { Critical damage at fracture in } \\
\text { compression: } D_{c}^{C}\end{array}$ & $\begin{array}{c}0.5 \\
\text { (Reference) }\end{array}$ & 0.4 & 0.45 & 0.55 & 0.6 & 0.65 \\
\hline Force at fracture $(\mathrm{kN})$ & 8.2 & 6.55 & 7.4 & 8,77 & 9.18 & 11.2 \\
\hline
\end{tabular}

Table 3. Six selected values of critical damage at fracture to investigate the model sensitivity on the predicted mechanical response. $D_{c}^{T}$ values were $-20 \%,-15 \%,-10 \%,-5 \%, 0 \%$ and $+5 \%$ $\left(D_{c}^{C}\right.$ kept equal to 0.5$)$ and $D_{c}^{C}$ values were $-20 \%,-10 \%, 0 \%,+10 \%,+20 \%$ and $+30 \%\left(D_{c}^{T}\right.$ kept equal to 0.95 ).

\section{Fracture simulation of proximal femur under one-legged stance quasi-static load}

In the present work, the ex-vivo experimental test performed previously by Keyak and Falkinstein [37] (Model B) (Fig. 2-a) was simulated. The authors tested the left femur of a male (age 61) under one-legged stance load till complete fracture.

In the present case, the 3D FE model was generated automatically from the geometry of the femur of a 61 year old male scanned to obtain a set of slices by QCT using software developed in-house based on a two-step procedure. First, the contours of the femur were extracted from the CT scan. Based on these contours, the surface of the bone was reconstructed, from which, in a second step, a FE mesh with 33150 parabolic tetrahedral elements was built (Fig. 2-b). Note that the FE femoral geometry retained here was not that used in the experimental tests. The geometry and mechanical properties of each individual femur are different in terms of mechanical response and fracture generated by applied loads. Nevertheless, the same bone properties of the same age were assigned and the overall structure of the proposed femur fracture modeling approach will remain unchanged whatever the specific characteristics of the femur under examination. The aim here was not to simulate the fracture behavior of Keyak and Falkinstein's femur nor to perform a direct comparative study with experimental results. 
The 3D model is partitioned into trabecular bone and cortical bone with the Hounsfield (HU) scale: HU>600 is taken as the cortical region [92] (Fig. 2-c). While the QCT measurement of human femur distinguishes between cortical and trabecular bone, partition of the femur into trabecular and cortical regions based on the empirical separation threshold (HU>600) may generate a certain inaccuracy in the cortical bone thickness, which can play an important role in bone resistance to fracture [9]. The accuracy of the cortical thickness measurement with QCT depends on the spatial resolution of the CT system, image noise, the positioning of specimens and the image processing software [59]. Also, Lee et al. [41] and Popescu et al. [60] reported that the spatial registration between CT scans of a patient's organ and the computer model of the organ is still a critical step in most computer-aided models accuracy. There is evidence that both bone regions individually contribute to bone strength because of their different material properties. Therefore, accurate imaging methods are needed to generate accurate representative FE femur models.

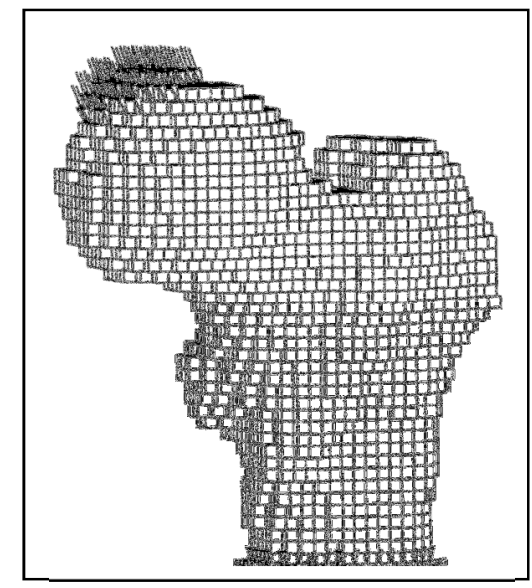

(a) 3D model of Keyak and Falkinstein [37].

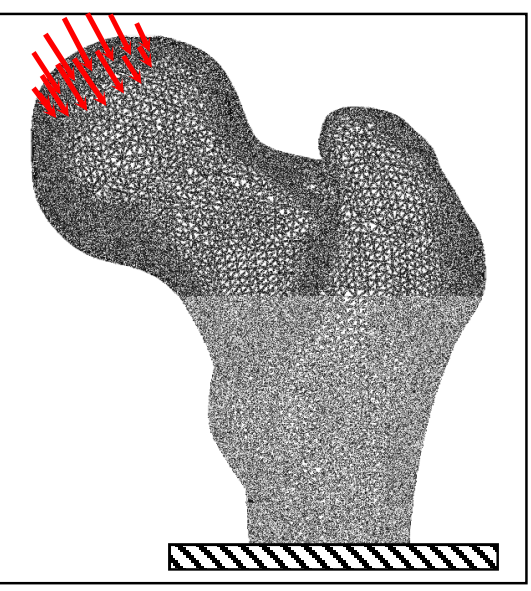

(b) Present 3D model.

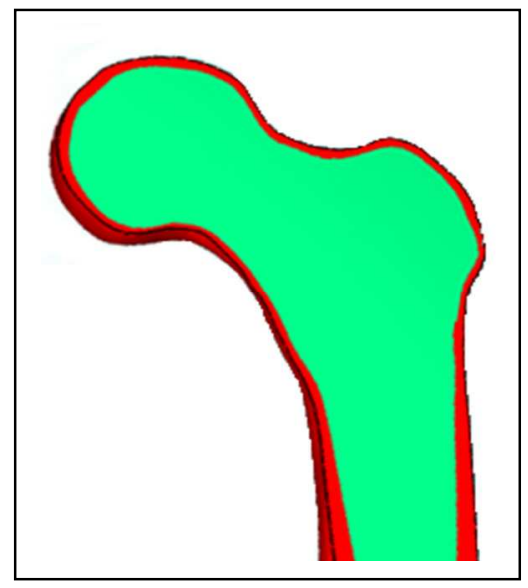

(c) Cross section showing femur partition into cortical and trabecular regions.

Figure 2. FE model of the left proximal femur of subject B (male, age 61) generated from QCT scan data obtained in vitro. The 3D model is partitioned into trabecular bone and cortical bone with the Hounsfield (HU) scale: HU>600 is taken as the cortical region [92]. Displacement was applied to the femoral head, as indicated by the arrows, and the distal portion of the model was restrained [37]. 
Nodal displacements $20^{\circ}$ from the shaft axis within the plane containing the shaft and cervical axes were applied incrementally to the top surface of the femur head till complete fracture and the model was restrained distally. Movement perpendicular to the applied displacements was permitted.

The same constitutive laws were used for trabecular and cortical bone but with different material averaged homogenized properties (Table 2).

\begin{tabular}{|lcccc|}
\hline & Notation & Cortical & Trabecular & Source \\
\hline General parameters & & & & \\
\hline Elastic modulus & $E(\mathrm{GPa})$ & 15 & 3 & {$[37]$} \\
\hline Poisson ratio & $V$ & 0.3 & 0.4 & {$[37]$} \\
\hline Age & $A g e$ & 61 & 61 & {$[37]$} \\
\hline Damage law parameters & & & & {$[56]$} \\
\hline $\begin{array}{l}\text { Critical damage at fracture } \\
\text { in tension }\end{array}$ & $D_{c}^{T}$ & 0.95 & 0.95 & {$[28]$} \\
\hline $\begin{array}{l}\text { Critical damage at fracture } \\
\text { in compression }\end{array}$ & $D_{c}^{C}$ & 0.5 & 0.5 & {$[87]$} \\
\hline Damage exponent & $n$ & 1.25 & 2 & {$[87]$} \\
\hline Damage strain threshold & $\varepsilon_{0}$ & 0.001 & 0.001 & {$[57,87]$} \\
\hline $\begin{array}{l}\text { Strain at fracture } \\
\text { in tension }\end{array}$ & $\varepsilon_{f-\text { true }}^{T}$ & 0.0157 & 0.025 & {$[57,87]$} \\
\hline $\begin{array}{l}\text { Strain at fracture } \\
\text { in compression }\end{array}$ & $\varepsilon_{f-\text { true }}^{C}$ & 0.025 & 0.04 & \\
\hline
\end{tabular}

Table 2. Material properties for bone used for the simulation.

\section{Results}

The predicted FE force-displacement curve based on Keyak and Falkinstein's specimen is plotted in Fig.3. The calculation time was about 15 min using an $8 \mathrm{~Gb}$ computer.

A typical experimental force-displacement curve of the tested specimen was reported by Keyak in [36] (Fig. 3). The curve predicted in the present study shows the same trend for curve shape and onset of yielding and fracture as the reported experimental one. The FE-based curve exhibits a sharp drop in force during failure that was nearly always observed during mechanical testing. 


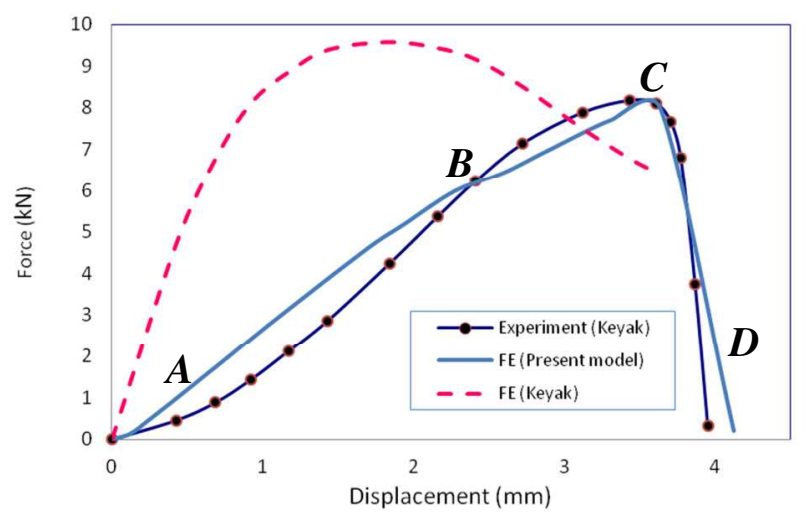

Figure 3. Predicted and experimental force-displacement curves obtained by Keyak reported in [36] and the present FE model. Point $B$ indicates the occurrence of yielding. Point $C$ indicates the occurrence of numerical fracture. From $C$ to $D$, the cracks propagate rapidly, leading to the drop of the curve (Complete fracture of the femur).

The propagation of the cracks and the distribution of the quasi-brittle damage within the femur in relation to the force-displacement curve position is plotted in Fig. 4. In the yielding stage $(B)$, the crack is initiated locally at the superior cortex located at the maximum tensile strain. After the yielding phase, the crack continues to grow rapidly, following a perpendicular path to the surface, leading to complete separation of the proximal femur. The results shown in Fig.4 indicate that the predicted fracture process occurred in two steps: (i) development of an initial macroscopic crack in the superior neck (Fig. 4) which corresponds to a local maximum tensile stress; (ii) development of a second macroscopic crack in the inferior femoral neck which corresponds to a local maximum compressive stress. The failure mechanism associated with a compressive stress state in the inferior region is the result of a material failure involving yielding when a shearing stress is superimposed on the compressive stress generated by the applied vertical displacement. In normal gait, the greatest stresses occur in the subcapital and midfemoral neck regions [46]. Within these regions, maximum compressive stresses occur inferiorly and smaller magnitude tensile stresses occur superiorly [46]. 


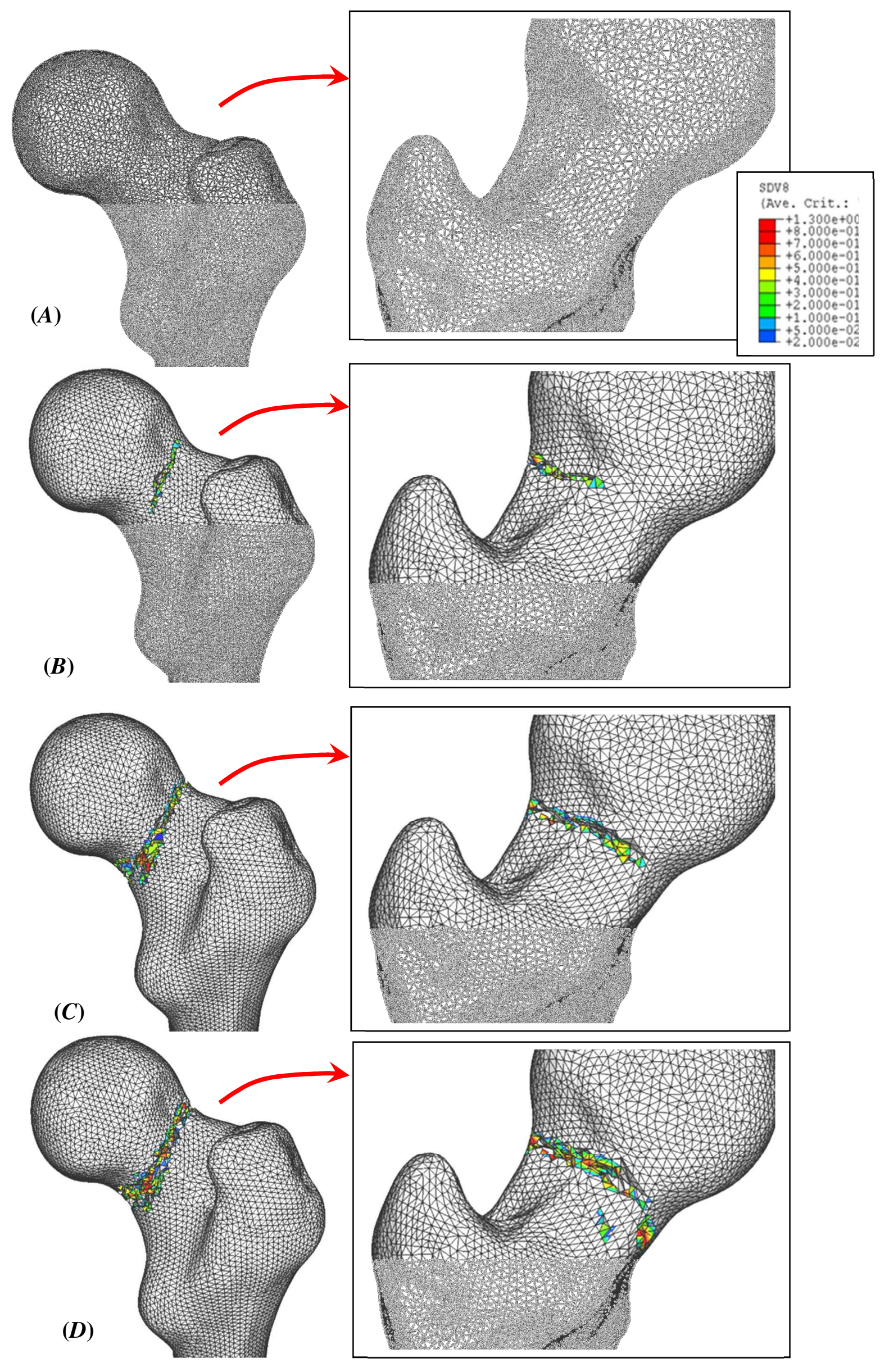


Figure 4. Crack propagation sequences in relation to the force-displacement curve and quasibrittle damage distribution.

The predicted complete fracture pattern of the femur is given in Figure 5. Depending on the boundary conditions, femoral geometry and the bone properties, different fracture patterns can be observed experimentally and the one obtained here corresponds to a subcapital fracture with stage II of the Garden classification (complete fracture with non-displacement). The stance configuration has been shown in previous studies to produce maximum shear stresses in the femoral neck region in a manner consistent with clinical subcapital fractures $[12,69]$ similar to the predicted one. This fracture pattern prediction is a useful decision-making tool to assist the surgeon in choosing a patient-specific operative treatment.
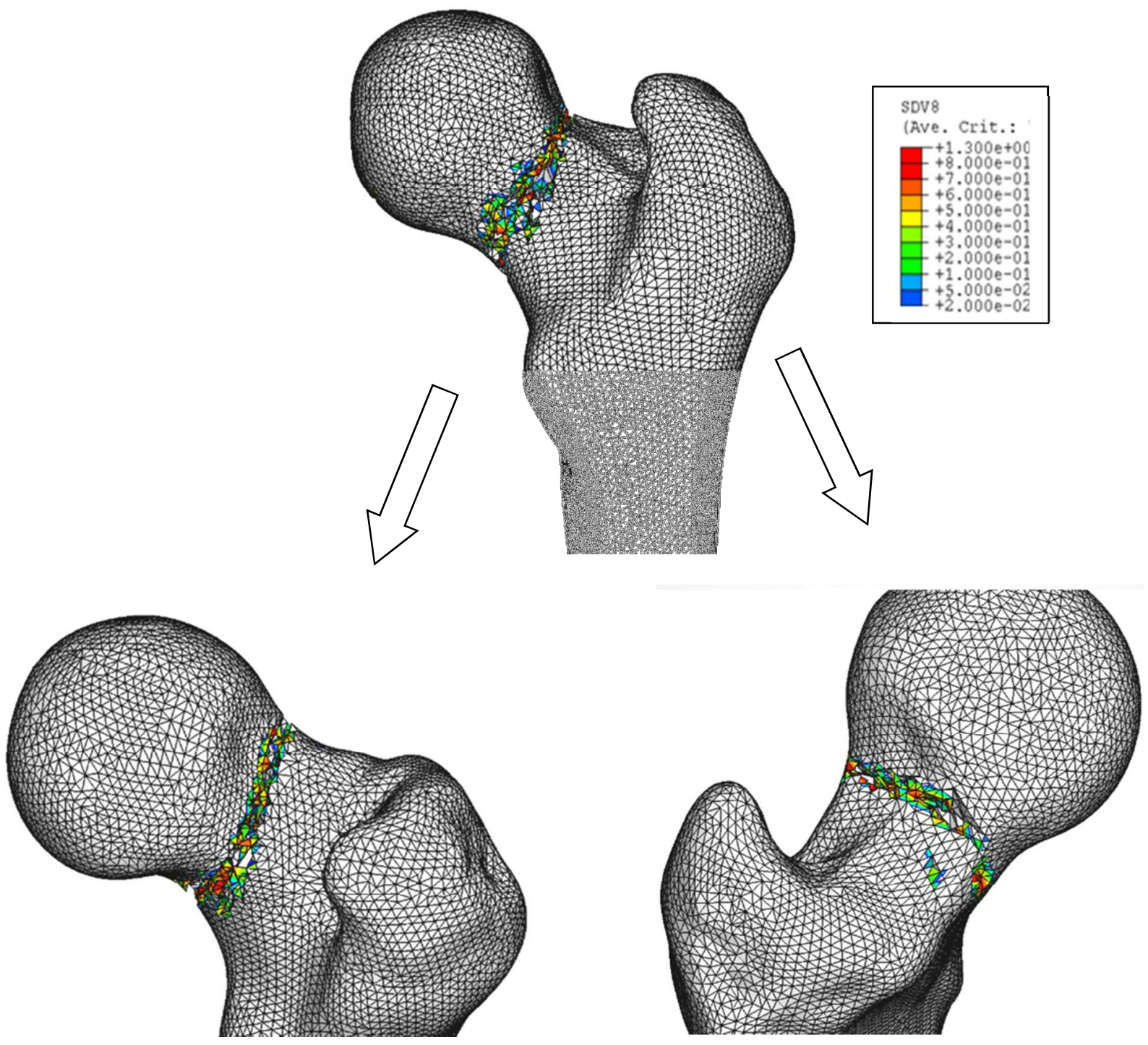

Figure 5. Predicted fracture pattern from different angles and quasi-brittle damage distribution. 


\subsection{Sensitivity analysis}

The results obtained from the SA simulations are plotted in Fig. 6.

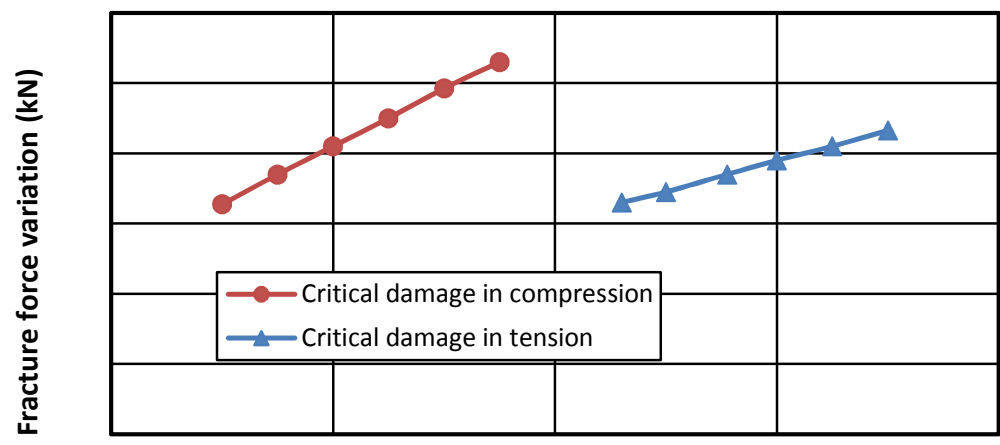

Critical damage at fracture

Figure 6. Fracture force versus the variation in the critical damage value in compression and tension.

The results revealed that variation in the critical damage generates a significant linear variation in the fracture force. An increase in the critical damage leads to an increase in the fracture force. This can be related to the fact that the critical damage value plays the main role on the onset of crack initiation and propagation within bone tissue. Lower values of critical damage lead to an early cracking process and then to a decreased force at fracture, whereas an increase in these parameters generates an increased resistance to fracture and therefore an increase in the fracture force. Predicted results revealed that the fracture patterns were very similar, and were not significantly affected by variation in the parameters. However, the rate of crack propagation increased with decreasing critical damage, suggesting that bone fracture may range from quasibrittle to brittle patterns depending on the bone material properties. From a material point of view, bone mineralization combined to fatigue damage accumulation has the combined effects of stiffening the tissue while making it more brittle. A bone that is highly mineralized is stiff and brittle and will require much less energy to fracture [14]. In addition, it has been proved that in elderly people, fatigue microcracks colocalize within highly mineralized regions of cortical bone tissue $[65,85]$. The critical damage value at fracture can represent these combined 
mineralization-fatigue damage effects in the framework of CDM. In conclusion, the sensitivity analysis shows that the precise identification of critical damage at fracture is necessary to increase the reliability of the prediction.

\section{Discussion}

The curve shape and onset of yielding of the predicted force-displacement curve shows the same trend as that observed experimentally [36]. The FE-based curve exhibits the sharp drop in force during failure that was nearly always seen during mechanical testing in the quasi-static experiment (low strain rates). A more physical approach to determine the value of the fracture force is to consider the maximum force from the force-displacement curve before the drop due to propagation of the cracks. The results of this paper show that the force-displacement curve predicted using the proposed model is more adequate than the results presented in [36-37], suggesting that a quasi-brittle isotropic model can predict plausible results related to the forcedisplacement curve. This result is in agreement with Verhulp et al.'s [83] findings. The authors suggested that the transverse modulus, introduced by assigning orthotropic material properties, does not play a very important role when physiological loading conditions such as single-legged stance are considered, since bone architecture is adapted to those conditions, but that differences between the isotropic and orthotropic models can be substantially larger for non-physiological loading such as lateral falls. Recently, patient-specific high order finite-element (FE) models of four human femurs based on quantitative QCT with inhomogeneous orthotropic and isotropic material properties were compared by Trabelsi and Yosibash [91, 92]. The authors compared the FE results to experimental observations to identify the influence of material properties on the models' predictions. They concluded that the strains and displacements computed by both models (inhomogeneous orthotropic and isotropic) match the FE results well, and both are in close agreement with the experimental results. 
The predicted fracture pattern corresponds to the path of the cracks after total separation of the fractured finite elements of the mesh. The present results predicted a progressive fracture process depending on the femur head displacement value (Fig. 4). The predicted crack path follows an oblique line with an angle to the horizontal plane greater than $60^{\circ}$ (Pauwels type III) from the inner surface of the neck (basal) to the outer surface towards the greater trochanter. A comparison between the predicted fracture patterns and experimental results is given in (Fig. 7). Although the loading conditions and femur geometries were different, a similar subcapital fracture pattern was obtained by Duchemin et al. [18] and Tanner et al. [70] during in vitro experiments performed on human femur under one-legged stance load.

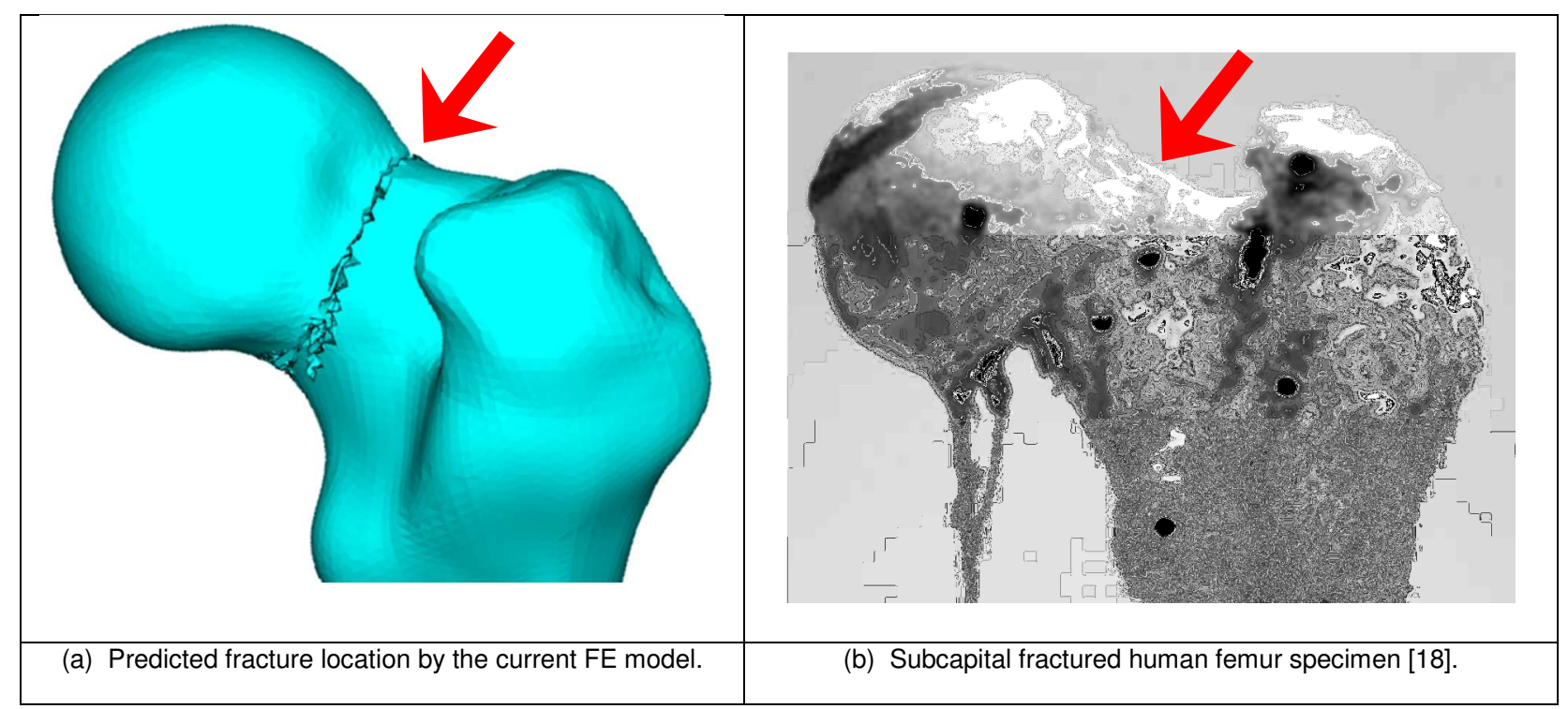

Figure 7. Comparison between predicted fracture pattern and experimental location of the femur fracture from Duchemin et al. [18]. 
The prediction of failure onset in human proximal femur at the organ level has instigated several research studies in recent years. In the literature basically two general approaches can be found: (i) post-processed fracture criteria (Table 1) and (ii) fracture mechanics based approaches $[2,47,78,81,84,89]$. Both methods are limited to describing the progressive initiation and propagation of multiple cracks within the bone leading to complete fracture. Recently, several anisotropic viscoelastic behavior laws coupled to damage for macroscopic bone at the organ level have been developed by various authors [22, 25, 54, 93-94]. However, the main limitations of application of these models are: (i) these sophisticated models need a large number of parameters (anisotropy, viscosity and damage) that are not available in the published literature and are very complicated to measure experimentally; (ii) techniques allowing for the simulation of crack initiation and propagation processes have not been developed, and (iii) the models have not been validated by simulation of a complete fracture (force-displacement curve and fracture pattern) of the human proximal femur.

The results predicted from FE simulations in the present study should be interpreted in accordance with the limiting assumptions of the model.

The first limitation to be considered is that only one femoral geometry was validated and although the modeled femur belonged to a person in the same age range as the femurs employed in the experimental tests, the femur was not the same in the two cases. More specific femur geometries based on QCT scans will be used in future work.

A second limitation lies in the application of the isotropic homogeneous hypothesis. It is well known that human femur is anisotropic and heterogeneous. A number of empirical relationships were proposed by several authors to convert the CT number of every FE of the mesh to bone material properties such as elastic modulus, strain at fracture and yield stress. However, the determination of material trajectories related to the trabecular orientations from clinical quantitative computed tomography (QCT) scans remains an open question and is 
difficult to apply in the framework of daily clinical applications. In addition, several investigations showed that in the case of one-legged stance, only local differences (strains, stresses and displacement) were observed and that the whole mechanical response of the femur (fracture force and fracture location) was quite similar [35, 48, 67, 76, 83, 91]. Verhulp et al. [83] suggested that differences between the isotropic and orthotropic models can be substantially larger for non-stance loading such as lateral falls. While the model proposed here can be extended to include material behavior and damage anisotropy, the overall structure of the proposed femur fracture modeling approach will remain unchanged.

The third limitation of the present study is that only one loading case (stance) was available for experimentation and no meaningful statistical analysis can be performed to substantiate the conclusions. Other loading configurations that induce high compressive and shear stresses and strains must also be considered in experiments to further validate the failure criteria in compression/shear. Also, further specific methods of assessing the material and fracture properties of femur are needed as these properties vary between anatomical locations $[8]$.

These limitations do not detract from the importance of the proposed CDM based femur fracture simulation. There will still be a need to perform FE simulations to predict the fracture conditions of human proximal femurs under a given boundary risk (stance, side fall). This study exemplifies that the current CDM approach is an enhanced, practical and simple model that can be applied in clinical computer-aided decision making. Further experimental tests are needed for validation and to investigate the anisotropic mechanical behavior of human femur, as well as reliable numerical mapping methods to assign anisotropic directions and the corresponding heterogeneous material properties. Also, before potential clinical implementation, further sensitivity analysis and validation is needed by performing several experiments with different bone samples and boundary conditions. 


\section{Acknowledgements}

This work was supported by the French National Research Agency (ANR) through the TecSan program (Project MoDos, $n^{\circ}$ ANR-09-TECS-018) and part of the Fractos project supported by the Region Centre (France). The authors is grateful to Dr Loulou H. for providing the femur mesh preparation.

\section{References}

1. Abaqus 6.9 Documentation, Analysis User's Manual.

2. Abdel-Wahab A.A. and Silberschmidt V.V. 2011, Numerical modeling of impact fracture of cortical bone tissue using X-FEM, J. of theoretical and applied mechanics, 49, 3, pp. 599-619.

3. Baca, V., Horak, Z., Mikulenka, P. and Dzupa, V. 2008, Comparison of an inhomogeneous orthotropic and isotropic material models used for FE analyses. Med. Eng. Phys. 30, 924-930.

4. Baudoin A, Skalli W, de Guise J, Mitton D. 2008, Parametric subject-specific model for in vivo 3D reconstruction using bi-planar X-rays : Application to the upper femoral extremity. Medical and Biological Engineering and Computing; 46.(8):799 - 805.

5. Bayraktar H.H., Morgan E.F., 2004, Niebur G.L., Morris G.E., Wong E.K. and Keaveny T.M., Comparison of the elastic and yield properties of human femoral trabecular and cortical bone tissue, J. Biomech.:37:27-35.

6. Bessho M., Ohnishi I., Matsuyama J., Matsumoto T., Imai K., Nakamura K. 2007, Prediction of strength and strain of the proximal femur by a CT-based finite element method. Journal of Biomechanics 40:1745-1753.

7. Bonnet A.S., Postaire M., Lipinski P. 2009, Biomechanical study of mandible bone supporting a four-implant retained bridge finite element analysis of the influence of bone anisotropy and foodstuff position. Medical Engineering and Physics; 31(7):806-15.

8. Brown, C.U., Yeni, Y., Norman, T.L., 2000. Fracture toughness is dependent on bone location: A study of femoral neck, femoral shaft, and the tibial shaft. Journal of Biomedical Materials Research 49,380-389.

9. Cheng X., Li J., Lu Y., Keyak J. and Lang T., 2007, Proximal femoral density and geometry measurements by quantitative computed tomography: Association with hip fracture, Bone 40, 169-174.

10. Cody D.D., Gross G.J., J. Hou F., Spencer H.J., Goldstein S.A., Fyhrie, D., 1999. Femoral strength is better predicted by finite element models than QCT and DXA. Journal of Biomechanics 32, 1013-1020.

11. Coelho P.G., Fernandes P.R., Rodrigues H.C., Cardoso J.B., Guedes J.M. 2009, Numerical modeling of bone tissue adaptation - a hierarchical approach for bone apparent density and trabecular structure. Journal of Biomechanics; 42(7):830-7. 
12. Cotton D.W., Whitehead C.L., Vyas S., Cooper C., Patterson E.A., 1994, Are hip fractures caused by falling and breaking or breaking and falling? Photoelastic stress analysis. Forensic Science International;65, 105-112.

13. Currey J. D., 1990. Physical characteristics affecting the tensile failure properties of compact bone. Journal of Biomechanics, 23(8):837-844.

14. Currey J.D., 2002. Bones: Structure and Mechanics. Princeton University Press, Princeton.

15. Chaboche J.L., 1981. Continuum damage mechanics: a tool to describe phenomena before crack initiation, Nucl Eng Des 64, pp. 233-247.

16. Cowin S. C. (Ed.) 2001. Bone mechanics handbook. CRC Press, Boca Raton, Florida.

17. Doblaré M., García J.M. 2002, Anisotropic bone remodeling model based on a continuum damage-repair theory. Journal of Biomechanics;35(1):1-17.

18. Duchemin L, Mitton D, Jolivet E, Bousson V, Laredo JD, Skalli W., 2008, An anatomical subject-specific FE-model for hip fracture load prediction. Comput Methods Biomech Biomed Engin. 11(2):105-11.

19. Dragomir-Daescu D., Op Den Buijs J., McEeligot S., Dai Y., Entwistle RC., Salas C., Melton III J. , Bennet E., Khosla S., Amin S., 2010, Robust QCT/FEA Models of Proximal Femur Stiffness and Fracture Load During a Sideways Fall on the Hip. Annals of Biomedical Engineering 201: 39(2):742-55.

20. Fernandes P, Rodrigues H, Jacobs CR. 1999, A model of bone adaptation using a global optimization criterion based on the trajectorial theory of Wolf. Computer Methods in Biomechanics and Biomedical Engineering, 2:125-38.

21. Fondrk, M.T., Bahniuk, E.H., Davy, D.T., Michaels, C. 1988. Some viscoplastic characteristics of bovine and human cortical bone. J. Biomech. 21(8), 623-630.

22. Fondrk, M. T., Bahniuk, E. H., and Davy, D. T. 1999a. A damage model for nonlinear tensile behavior of cortical bone. Journal of Biomedical Engineering, 121:533-541.

23. Fondrk, M. T., Bahniuk, E. H., and Davy, D. T. 1999b. Inelastic strain accumulation in cortical bone during rapid transient tensile loading. Journal of Biomechanical Engineering, 121:616-621

24. Ford C.M., Keaveny T.M., Hayes W.C. 1996, The effect of impact direction on the structural capacity of the proximal femur during falls. J Bone Miner Res. 11:377-83.

25. Garcia D, Zysset P, Charlebois M, Curnier A. 2009. A three-dimensional elastic plastic damage constitutive law for bone tissue. Biomech Model Mechanobiol. 8(2):149-165.

26. Gray H.A., Taddei F., Zavatsky A.B., Cristofolini L, Gill H.S. 2008, Experimental validation of a finite element model of a human cadaveric tibia. Journal of Biomechanical Engineering;130(3):031016.

27. Hambli R, Bettamer A, Allaoui S. 2012, Finite element prediction of proximal femur fracture pattern based on orthotropic behaviour law coupled to quasi-brittle damage. Med Eng Phys. 34(2):202-210.

28. Hambli R., 2011a, Multiscale prediction of crack density and crack length accumulation in trabecular bone based on neural networks and finite element simulation, International Journal for Numerical Methods in Biomedical Engineering (27):4, 461-475.

29. Hambli R., 2011b, Apparent damage accumulation in cancellous bone using neural networks. J Mech Behav Biomed Mater 4(6):868-78. 
30. Hellmich, C., Kober, C. and Erdmann, B. 2008, Micromechanics-based conversion of CT data into anisotropic elasticity tensors, applied to FE simulations of a mandible. Ann. Biomed. Eng. 36, 108-122.

31. Juszczyk M.M., Cristofolini L., Viceconti M., 2011, The human proximal femur behaves linearly elastic up to failure under physiological loading conditions, J. Biomech. $11 ; 44(12): 2259-66$.

32. Kaneko T.S., Pejcic M.R., Tehranzadeh J., Keyak J.H., 2003, Relationships between material properties and CT scan data of cortical bone with and without metastatic lesions, Med Eng Phys., 25(6):445-54.

33. Kotha S. P. and Guzelsu N., 2003. Tensile damage and its effects on cortical bone. Journal of Biomechanics, 36(11):1683-1689.

34. Keaveny, T. M., Wachtel, E. F., and Kopperdahl, D. L., 1999, Mechanical behavior of human trabecular bone after overloading. Journal of Orthopaedic Research, 17:346-353.

35. Keyak, J., Meagher, J. Skinner, H. and Mote, J. 1990 Automated three-dimensional finite element modelling of bone: a new method. ASME J. Biomech. Eng. 12, 389-397.

36. Keyak J.H. 2001, Improved prediction of proximal femoral fracture load using nonlinear finite element models. Med Eng Phys;23:165-73.

37. Keyak J.H., Falkinstein Y., 2003. Comparison of in situ and in vitro CT scan-based finite element model predictions of proximal femoral fracture load, Medical Engineering \& Physics $25781-787$.

38. Koivumäki JE, Thevenot J, Pulkkinen P, Kuhn V, Link TM, Eckstein F, Jämsä T., 2012, Ct-based finite element models can be used to estimate experimentally measured failure loads in the proximal femur. Bone, 50(4):824-9.

39. Koivumaki J. E., Thevenot J., Pulkkinen P., Salmi J.A., Kuhn V., Lochmuller E.M., Link T. M., Eckstein F. and Jamsa T. 2010, Does femoral strain distribution coincide with the occurrence of cervical versus trochanteric hip fractures? An experimental finite element study. Med Biol Eng Comput, 48, 711-7.

40. Kowalczyk P. 2010, Simulation of orthotropic microstructure remodeling of cancellous bone. Journal of Biomechanics;43(3):563-9.

41. Lee Y.S., Oh S.H., Seon J.K., Song, E.K. and Yoon T.R. 2006, 3D femoral neck anteversion measurements based on the posterior femoral plane in ORTHODOC system. Med Biol Eng Comput 44:895-906.

42. Lemaitre J., 1985. A continuous damage mechanics model for ductile fracture, Journal of Engineering Materials and Technology, 107: 83-89.

43. Link M., Vieth V., Langenberg R., Meier N., Lotter A., Newitt D., Majumdar S. 2003, Structure analysis of high resolution magnetic resonance imaging of the proximal femur: in vitro correlation with biomechanical strength and BMD. Calc. Tissue International, 72:156165.

44. Lotz J.C, Cheal E.J., Hayes W.C. 1991a, Fracture prediction for the proximal femur using finite element models: part I-linear analysis. J Biomech Eng;113:353-60.

45. Lotz J.C., Cheal E.J., Hayes W.C. 1991b, Fracture prediction for the proximal femur using finite element models: part II—nonlinear analysis. J Biomech Eng;113:361-5.

46. Lotz J.C., Cheal E.J., Hayes W.C., 1995. Stress distributions within the proximal femur during gait and falls: implications for osteoporotic fracture. Osteopor Int; 5:252-61. 
47. Malik L., Stover M., Martin B. and Gibeling C., 2003, Equine cortical bone exhibits rising Rcurve fracture mechanics. J Biomech, 36:191-8.

48. Martelli, S., Taddei, F., Varini, E., Cristofolini, L., Gill, L. and Viceconti, M. 2005, Accuracy of subject specific finite-element models of long bones from CT data: an in vitro study. Proc. ICCB II 1, 251-265.

49. MacNeil J.A. and Boyd S.K., 2008, Bone strength at the distal radius can be estimated from high-resolution peripheral quantitative computed tomography and the finite element method. Bone. 42(6):1203-13.

50. Mazars J., Pijaudier-Cabot G., 1996, From Damage to fracture mechanics and conversely: a combined approach. International Journal Solid Structure; 33:3327-3342.

51. Miller Z, Fuchs M, Arcan M. 2002. Trabecular bone adaptation with an orthotropic material model. Journal of Biomechanics, 35(2):247-56.

52. Murakami, S. and Liu, Y., 1995. Mesh-dependence in local approach to creep fracture. Int. J. Damage Mech, 4, 230-250.

53. Nagaraja S., Couse T. L., Guldberg R. E., 2005. Trabecular bone microdamage and microstructural stresses under uniaxial compression, Journal of Biomechanics 38 707-716.

54. Natali A, Carniel E, Pavan P. 2008 Constitutive modelling of inelastic behaviour of cortical bone. Med Eng Phys 30(7):905-912

55. Ota T., Yamamoto I., and Morita R. 1999, Fracture simulation of femoral bone using finiteelement method: How a fracture initiates and proceeds, Bone and Min. Metab. 17(2):108-12.

56. Pattin, C.A., Caler, W.E., Carter, D.R., 1996. Cyclic mechanical property degradation during fatigue loading of cortical bone. Journal of Biomechanics 29, 69-79.

57. Parsamian, G. P., 2002, Damage mechanics of human cortical bone. Phd Thesis, College of Engineering and Mineral Resources, West Virginia University.

58. Peng, L., Bai, J., Zeng, X. and Zhou, Y. 2006 Comparison of isotropic and orthotropic material property assignments on femoral finite element models under two loading conditions. Med. Eng. Phys. 28, 227-233.

59. Prevrhal S., Shepherd J. A., and Genant H. K., 2003, Accuracy of CT-based thickness measurement of thin structures: Modeling of limited spatial resolution in all three dimensions, Med. Phys. 30(1):1-8.

60. Popescu, F. C. Viceconti, M. Traina, F. Toni, A. 2005, Evaluation of achievable registration accuracy of the femur during minimally invasive total hip replacement Med Biol Eng Comput. 43, 421-30.

61. Reilly, D.T., Burstein, A.H., 1974. Review article. The mechanical properties of cortical bone. J. Bone Jt. Surg. Am. 56, 1001-1022.

62. Reilly DT, Burstein AH. 1975, The elastic and ultimate properties of compact bone tissue. J Biomech 8, 393-405.

63. Saanouni, K., Chaboche, J.-L. and Lesne, P.M., 1989. On the creep crack-growth prediction by a non local damage formulation. Eur. J. Mech. A/Solids, 8, 437-459.

64. San Antonio T, Ciaccia M, Müller-Karger C, Casanova E., 2011, Orientation of orthotropic material properties in a femur FE model: A method based on the principal stresses directions. Med Eng Phys. (on line).

65. Schaffler MB, Choi K, Milgrom C. 1995. Aging and matrix microdamage accumulation in human compact bone. Bone 17:521 - 525 . 
66. Schneider R, Faust G, Hindenlang U, Helwig P. 2009. Inhomogeneous, orthotropic material model for the cortical structure of long bones modeled on the basis of clinical CT or density data. Computer Methods in Applied Mechanical Engineering, 198(27-29):2167-2174.

67. Schileo, E., Taddei, F., Malandrino, A., Cristofolini, L. and Viceconti, M. 2007 Subjectspecific finite element models can accurately predict strain levels in long bones. J. Biomech. 40, 2982-2989.

68. Schileo E., Taddei F., Cristofolini L., Viceconti, M., 2008. Subject-specific finite element models implementing a maximum principal strain criterion are able to estimate failure risk and fracture location on human femurs tested in vitro. J Biomech 41(2), 356-67.

69. Smith M.D., Cody D.D., Cooperman A.M., Goldstein S.A., Matthews L.S., Flynn M.J., 1992, Proximal femur bone density and its correlation to fracture load and hip screw penetration load. Clinical Orthopaedics Related Research, 283, 244-251.

70. Tanner D.A., Kloseck M., Crilly R.G., Chesworth B. and Gillilan J., 2010. Hip fracture types in men and women change differently with age, BMC Geriatrics, 10:12.

71. Taylor, W. R., Roland, E., Ploeg, H., Hertig, D., Klabunde, R., Warner, M. D., Hobatho, M. C., Rakotomanana L. and Clift S.E. 2002, Determination of orthotropic bone elastic constants using FEA and modal analysis. J. Biomech. 35, 767-773.

72. Taylor D., and Lee T.C., 2003. A crack growth model for the simulation of fatigue in bone. International Journal of Fatigue 2, 387-395.

73. Tabor Z, Rokita E. 2007, Quantifying anisotropy of trabecular bone from gray-level images. Bone, 40(4):966-72.

74. Taddei F., Cristofolini L., Martelli S., Gill H. and Viceconti M. 2006, Subject-specific finite element models of long bones: an in vitro evaluation of the overall accuracy. J. Biomech. 39:2457-2467.

75. Trabelsi, N., Yosibash, Z. and Milgrom, C. 2009 Validation of subject-specific automated pFE analysis of the proximal femur. J. Biomech. 42, 234-241.

76. Trabelsi N, Yosibash Z., 2011, Patient-specific finite-element analyses of the proximal femur with orthotropic material properties validated by experiments, $J$ Biomech Eng.;133(6):061001.

77. Tellache M., Pithioux M., Chabrand P., Hochard C., 2009, Femoral neck fracture prediction by anisotropic yield criteria, European Journal of Computational Mechanics 18, 1,33-41.

78. Ural A. and Vashishth D. 2007, Anisotropy of age-related toughness loss in human cortical bone: A finite element study. Journal of Biomechanics, 40:1606-1614.

79. de Vree, J.H.P., Brekelmans, W.A.M. and van Gils, M.A.J., 1995. Comparison of nonlocal approaches in continuum damage mechanics. Comp. Struct., 55, 581-588.

80. Vashishth D.J., Koontz Qiu S., Cannon-Lundin D., Yeni Y.N., Schaffler M.B., Fyhrie D.P. 2000, In vivo diffuse damage in human trabecular bone. Bone. 26 (No 2):147-152.

81. Vashishth D., Tanner E. and Bonfield W. 2003, Experimental validation of a microcrackingbased toughening mechanism for cortical bone. J Biomech, 36(1):121-124.

82. Vashishth D., Behiri J.C., W. Bonfield W., 1997, Crack growth resistance in cortical bone: Concept of microcrack toughening, J Biomech, 30,( 8):763-769.

83. Verhulp, E., van Rietbergen, B. and Huiskes, R. 2006. Comparison of micro-level and continuum level voxel models of the proximal femur. J. Biomech. 39, 2951-2957. 
84. Wang X., Zauel R. and Fyhrie D.P., 2008, Post failure modulus strongly affects microcracking and mechanical property change in human iliac cancellous bone: A study using a 2D nonlinear finite element method, Journal of Biomechanics 41, 2654- 2658.

85. Wasserman N, Yerramshetty J, Akkus O., 2005, Microcracks colocalize within highly mineralized regions of cortical bone tissue, Eur J Morphol. 42(1-2):43-51.

86. Wirtz, D. C., Pandorf, T., Portheine, F., Radermacher, K., Schiffers, N., Prescher, A., Weichert, D. and Niethard, F. U., 2003, Concept and development of an orthotropic FE model of the proximal femur. J. Biomech. 36, 289-293.

87. Wolfram U., Wilke H.J., Zysset P.K. 2011, Damage accumulation in vertebral trabecular bone depends on loading mode and direction. J Biomech. 7, 44(6):1164-9

88. Yang H., Shen, L. Demetropoulos K., King I., Kolodziej P., Levine S. and Fitzgerald J. 1996, The relationship between loading conditions and fracture patterns of the proximal femur. Journal of Biomechanical Engineering;118:575-578.

89. Yang D., Cox N., Nalla K. and Ritchie O., 2006, Re-evaluating the toughness of human cortical bone, Bone 38:878-887.

90. Yang H, Ma X, Guo T. 2010, Some factors that affect the comparison between isotropic and orthotropic inhomogeneous finite element material models of femur. Medical Engineering and Physics;32(6):553-60.

91. Yosibash Z., Tal D. and Trabelsi N., 2010, Inhomogeneous orthotropic material properties high-order finite-element analysis with inhomogeneous orthotropic material properties, Phil. Trans. R. Soc. A 368, 2707-2723.

92. Yosibash, Z., Trabelsi, N. and Milgrom, C. 2007, Reliable simulations of the human proximal femur by high-order finite element analysis validated by experimental observations. J. Biomech. 40, 3688-3699.

93. Zysset PK 1994. A constitutive law for trabecular bone. Ph.D. thesis, Ecole Polytechnique Federale de Lausanne.

94. Zysset PK, Curnier A 1995. An alternative model for anisotropic elasticity based on fabric tensors. Mech Mater 21(4):243-250. 